\title{
The Design of Active Labour Market Policies. What Matters and What Doesn't?
}

\author{
By
}

Bart Cockx ${ }^{1}$

\author{
IRES and Department of Economics \\ Université Catholique de Louvain
}

\begin{abstract}
:
A first objective of this paper is to emphasise the role of a correct diagnosis of unemployment persistence for the design of effective active labour market policies. A second is to stress the importance of adequate incentives for programme administrators of active labour market policies, and that this may well be more important than providing adequate incentives to the unemployed. To illustrate this, we summarise two case studies evaluating active labour market policies in Belgium. The first one evaluates a work experience programme for welfare recipients. The second one analyses the short-term effect of vocational training programmes for unemployed workers on the probability of leaving unemployment. Finally, we invite economists to think harder about well designed performance-standards systems. We provide some guidelines for this research programme.
\end{abstract}

Keywords: Active labour market policies, unemployment, policy design.

JEL Classification: H43, H53, I38, J24, J68.

1 This research was supported by the Belgian Programme on Inter-university Poles of Attraction initiated by the Belgian State, Prime Minister's Office, Science Policy Planning. The author thanks Bruno Van der Linden, Muriel Dejemeppe, Yves Saks and the participants to the International Conference on Institutional and Financial Incentives for Social Insurance, organised in Louvain-la-Neuve, December 11 and 12, 1998, for helpful comments. 


\section{Introduction}

The last two decades the design of unemployment benefit schemes has been criticised uninterruptedly. These schemes have been conceived at a time when high and structural unemployment did not exist. They aimed at providing insurance against the risk of temporary income loss caused by involuntary lay-off. They were not designed to deal with persistent income loss facing the current jobless.

There is a widespread belief that it is partly the benefit scheme itself that causes a "culture" of benefit dependency and therefore persistent unemployment. Schemes need reform to induce the unemployed to find jobs as quickly as possible, countering thereby this process of dependency. This has lead to two types of policy reforms. The first type consists in sanctioning unemployed workers. These sanctions consist of unconditional or conditional benefit reductions. If conditional, these benefit reductions typically depend on the elapsed unemployment duration, on the refusal of a "suitable" job offer, or on the lack of proof of sufficient job search effort. The effectiveness of these sanctions is discussed in the paper of Van der Linden and Dor (1998). The second type of policy reform proposal is to activate the unemployed by mandating participation to active labour market programmes, such as job search, work experience and vocational training programmes.

The activation of the unemployed is a policy advice that is clearly based upon the commonly held view that long spells of unemployment are a cause of unemployment persistence rather than its consequence. Sneessens 1994, Drèze and Sneessens 1997, for instance, call this view in question, at least for countries like France or Belgium. Moreover, there are other views on the causes of unemployment persistence. A first objective of this paper is to emphasise the role of a correct diagnosis of unemployment persistence for the design of effective active labour market policies.

A second objective of this paper, is to stress the importance of the design of adequate incentives for programme administrators of active labour market policies, and that this may well be more important than providing adequate incentives for the unemployed. Programme administrators may use a programme in order to serve their own objectives, rather than the programme objectives. What use is it to encourage workers to participate in programmes if these do not enhance their employability, but merely serve the interests of programme administrators? Moreover, current performance-standards systems, attempting to bring programme administrators to the type of discipline that markets bring to firms, are often not well designed and may do more harm than good. We therefore invite economists to think harder about well designed performance-standards systems. We provide some guidelines for this research programme.

In order to illustrate the crucial role of correct incentives for programme administrators, we summarise two case studies evaluating active labour market policies in Belgium. The first one evaluates a work experience programme for welfare recipients. It is a clear example of how an improperly designed subsidy scheme can serve objectives of administrators rather than those of the programme. The second case study analyses the short-term effect of vocational training programmes for unemployed workers on the probability of leaving unemployment. In spite of, 
or should we say thanks to, no explicit performance-standards system for programme administrators, the vocational training programmes are found to be effective.

The paper is structured as follows. First, we underline how the effectiveness of particular labour market policies is related to a correct diagnosis of the underlying causes of unemployment persistence. The Belgian case is focused upon. In Section 3 we discuss what role economic incentives can play in the effectiveness of active labour market policies. A final section concludes.

\section{Policy Effectiveness and the Underlying Causes of Unemployment Persistence}

A correct diagnosis of the underlying causes of unemployment persistence in Europe is crucial for an effective design of active labour market policies. Before we underpin this position we want to preclude from the critique that unemployment persistence is eventually a consequence of wage rigidity, or more generally of too strict labour market regulations. In this view, optimal policy simply consists in trying to revert to the first-best competitive economy. In such an economy, flexible wages and a perfectly de-regulated labour market have completely absorbed unemployment. If so, the design of active labour market policies can logically not depend on the underlying causes of unemployment persistence. Active labour market policies are then justified to the extent that they can restore other market failures. For instance, job search programmes can improve the functioning of the labour market in that they can temper the inefficiencies induced by information asymmetries between workers and firms. Subsidy schemes for vocational training can be a response to capital market imperfections or to the existence of poaching externalities between firms providing on-the-job training (see Booth and Snower 1996).

I have two responses to this critique. First, even if de-regulation could eliminate unemployment it is not necessarily desirable from a normative point of view. For, the reduction of unemployment persistence has to be to be traded-off against more income inequality and poverty. Second, economists generally over-emphasise the gains in terms of unemployment reductions or more general measures of efficiency to be obtained from labour market de-regulation and under-estimate the costs (OECD 1990, 1994).

Labour market regulations can enhance efficiency in a number of ways. For instance, laws that limit dismissal, income protection programmes and maternity leave programmes create long-term incentives for employers and workers to invest in human capital and provide opportunities to children of these workers to invest in health and education paying off in terms of future adult productivity. Moreover, regulations can improve the quality of job matches, reduce turnover costs faced by firms, reduce the risk facing workers and families, and preclude employers from monopsonistic behaviour (Blank and Freeman 1994, Gregg and Manning 1996). Once we agree that labour market regulation cannot be the sole explanation of the high and persistent unemployment in Europe, and that some amount of regulation can even reduce unemployment, we are in a position to accept that a policy aiming at a reversion to the first best competitive economy is not necessarily efficient. In such a second-best (or third-best) world active labour market policies may have a role to play in tackling 
unemployment. Moreover, we argue that the optimal design of active labour market policies in such a world will depend on the underlying causes of unemployment persistence.

We consider four explanations of unemployment persistence in Europe and their implications for the design of active labour market policies. We do not claim that these explanations exhaust the list of possible causes. The first explanation is essentially the explanation given in the introduction, which says that it is essentially the inadequate design of the unemployment benefit schemes that is responsible for an increasing dependency of unemployed workers. The second explanation is the increasingly popular view that the persistence in unemployment is a consequence of a structural mismatch between the demand and the supply for low skilled workers. Finally, we consider two explanations that relate the persistence of high unemployment to depressed capital accumulation and therefore to the slowdown of economic growth. The explanations differ from each other in the way in which these capital shortages are generated. Daveri and Tabellini (1997) argue that the excessively high costs of labour has reduced the incentive to invest and thus to grow. Drèze (1997), and Shadman-Mehta and Sneessens (1998) relate under-investment to a co-ordination failure taking the form of a combination of current and future expected supply constraints induced by downward rigid real wages. We will assume that the latter two explanations in combination with the phenomenon of job competition can explain why the lower skilled workers are mainly affected by the unemployment risk $^{2}$. Job competition is the phenomenon that higher skilled workers crowd out lower skilled workers in a competition for jobs.

The observed negative duration dependence of the exit rates out of unemployment supports the thesis that the unemployment benefit scheme, requiring workers not to work to be eligible, induces dependency and therefore unemployment persistence (Layard, Nickell and Jackman 1991). The arguments are twofold. First, unemployment induces a process of de-motivation or habituation, leading to reductions in job search activity and therefore to a declining probability of leaving unemployment. Alternatively, a long spell of unemployment leads to skill deterioration and loss of work habits. This process downgrades the value of the worker on the labour market, and, if potential employers observe it, the latter will be less inclined to hire the less productive worker. The latter process can be reinforced in a context of imperfect information, in which the employer is imperfectly informed about the productivity of applicants. In such an environment the employer may use unemployment duration as a signal for the quality of the worker and therefore for recruitment purposes rank candidates according their unemployment duration (Blanchard 1991 and Blanchard and Diamond 1994). This recruitment behaviour can induce negative duration dependence in the hiring rates, even if the former explanations have only a negligible impact.

Layard, Nickell and Jackman (1991) have argued that these negative effects on the employability of unemployed workers are one of the main channels of unemployment persistence in Europe. According these authors, a succession of negative economic shocks, combined with the higher mentioned disemployability effects has reduced the effective labour supply and consequently the rise of persistent long-term unemployment during the eighties. When economic activity resumes, the long-term unemployed are no longer effective candidates to fill job vacancies, which leads to labour shortages even when unemployment is high. Moreover, the lack of competitiveness of the unemployed "outsiders" reinforces the bargaining power of the employed "insiders" in their demand for salary increases, thereby

\footnotetext{
${ }^{2}$ These two explanations need not necessarily be linked to job competition. They can equally be combined with the skill mismatch or the negative duration dependence diagnoses.
} 
tempering employment growth. These two factors inhibit the unemployment rate to return to its initial equilibrium level.

What are the policy prescriptions implied by this diagnosis? If unemployment generates a process of de-motivation, deterioration of skills and loss of work experience, conditioning receipt of benefits on participation in active labour market programmes is a way out. Temporary work experience programmes work as a preventive policies, up-keeping skills and work habits. If the above mentioned process has been ongoing for some time, curative policies, such as training are more adapted. Long-term unemployed or dislocated workers may first need to participate in a training programme to upgrade lost skills. Job-search programmes are called for if de-motivation is a main cause of unemployment dependency. Finally, if habituation to unemployment is a problem, mandatory participation to these programmes may be required (see Calmfors 1994, p.24). Note many of the Belgian active labour market policies share similar features (see Dejemeppe and Cockx 1998a). It is therefore important to verify whether the diagnosis on which these policy prescriptions is based, can be supported by empirical facts. This is where we now turn to.

This diagnosis of unemployment persistence is largely supported by the observed negative duration dependence in the aggregate exit rates out of unemployment. This negative duration dependence can, however, be "spurious". The decline in the aggregate exit rates may merely reflect a sorting process induced by heterogeneity in the unemployment population. If workers entering the unemployment state are heterogeneous, the workers with the most favourable labour market characteristics, the "high skilled" say, leave this state rapidly, leaving behind the "low skilled" workers. Even if individual exit probabilities are constant with duration, this sorting process will cause the aggregate exit rate to decrease with duration, because the aggregate exit rate is simply equal to the average exit rate of those remaining unemployed. The latter declines as a consequence of the gradual decline of the "skill level" over the unemployment spell induced by the sorting process.

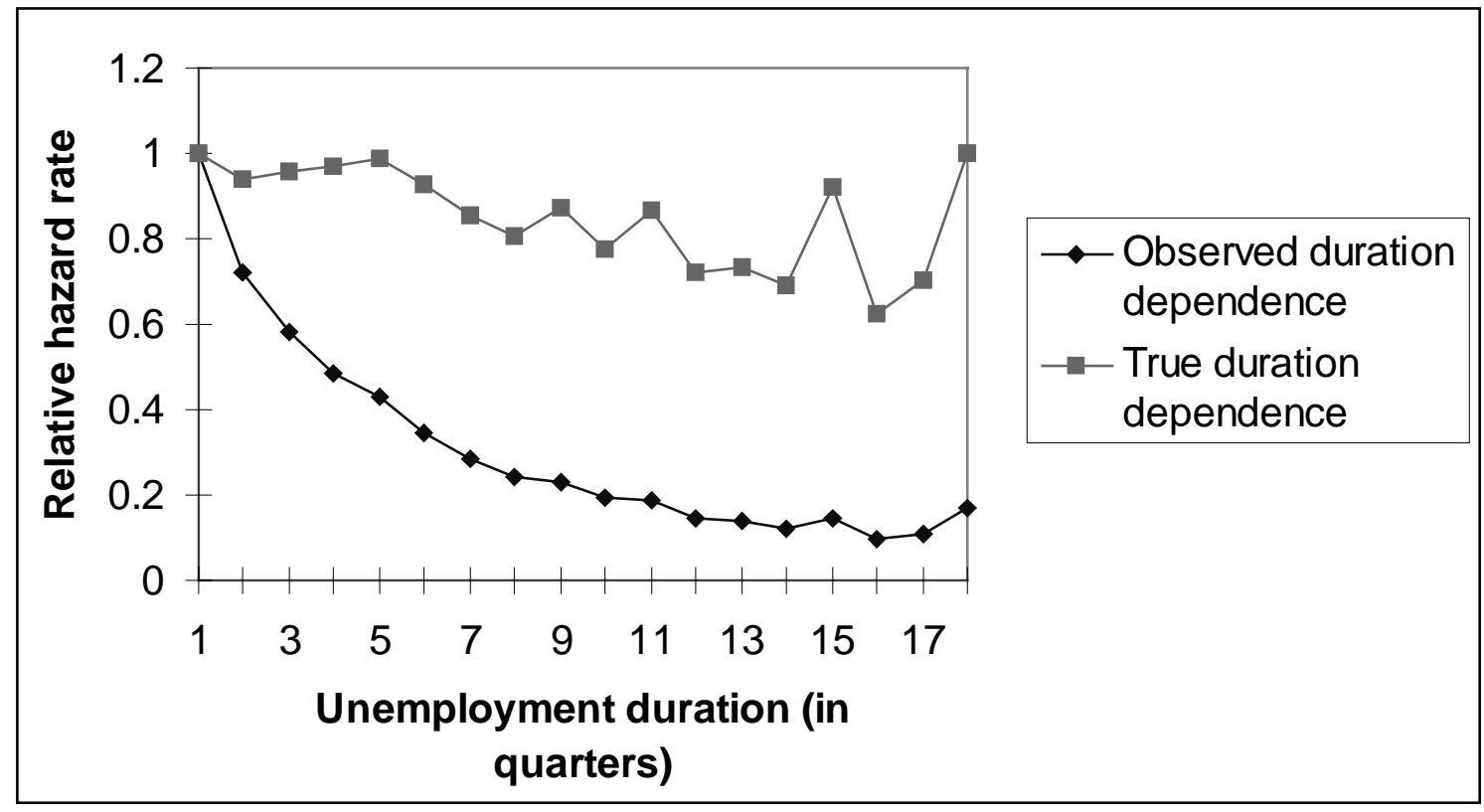

Dejemeppe and Cockx (1998b) have disentangled "true" from "spurious" duration dependence of the exit rates for a sample of unemployed men living in Wallonia (Belgium) in the June 1989 - February 1994 period. This period covers a downturn of the business cycle. 
Figure 1 summarises their findings. In order to focus on the dependency question the hazard rates out of unemployment are normalised to one at the beginning of the unemployment spell. After an elapsed duration of three and a half years, the observed aggregate hazard rate has declined to a level that is merely $10 \%$ of the initial rate. After correction for "spurious" duration dependence, the hazard rate is roughly constant during the first one and a half years, where after it decreases gradually to a level that is only $30 \%$ below its initial rate after three and a half years. The strong decrease in the observed aggregate hazard rate is therefore essentially the result of an important heterogeneity in the hazard rate out of unemployment from in the beginning of the unemployment spell.

On the basis of these results, we conclude that negative duration dependence of the exit rates out of unemployment, even if it plays a role, cannot be the main channel of unemployment persistence in Belgium. To the extent that the design of active labour market policies crucially depends on the diagnosis of unemployment persistence, these results call for policy reform in Belgium $^{3}$. Moreover, these findings call for prudence and at least for some differentiation in the policy prescriptions according to the nature of unemployment persistence in the EU . Similar findings are reported for other European countries (Machin and Manning 1999). On the other hand, true negative duration dependence is far more important in the UK (van den Berg and van Ours 1994 and 1996).

An alternative theory, that is compatible with the high degree of heterogeneity in the exit rates out of unemployment, is the increasingly popular view of a structural skill mismatch (cf. e.g. Sneessens 1994, Drèze and Sneessens 1997, Van der Linden 1997, Berman, Bound and Machin 1998). According to this view technological change that is biased in favour of skilled labour, perhaps combined with a globalisation of the world economy, has led to a structural collapse in the demand for unskilled workers. This collapse in the demand, jointly with a wage structure that is downwards rigid, causes high unemployment to be concentrated on the less skilled experiencing long spells of unemployment. Long-term unemployment is here a consequence of the lack of demand for the services for low skilled workers rather than of a process inducing negative duration dependence in the exit rates out of unemployment.

Policy prescriptions are different if this is the correct diagnosis of unemployment persistence. Temporary work experience programmes are unlikely to be very effective. For, to the extent that the work experience programme has little training content, it does not impact on the structural imbalance between demand and supply of labour. Schooling and training programmes, on the other hand, are more promising, as they can reduce the gap between the demand and supply of skills. However, there exist limits to the returns of training, especially for youth tired of being in school. Drèze and Malinvaud (1994) propose therefore permanent reductions of labour costs targeted to low-wage workers in order to create a demand for low skilled jobs. On-the-job training can be a valuable complement to these policies.

The central Belgian authorities currently provide reductions in the social insurance contributions of employers for low-wage workers. The amount of the reductions are, however, still quite modest and outlays on them are significantly lower than on the ("Maribel") across the board subsidies in the industrial sector (Dejemeppe and Cockx 1998a, p.197). Moreover, even if Belgium spends more (1,4\% of GDP in 1995) on active labour market policies than the EU on average (1,1\% of GIP), its composition does not accommodate to the diagnosis of

\footnotetext{
${ }^{3}$ One can argue that the negligible true negative duration dependence in the exit rates out of unemployment in Belgium, is a consequence of the actual labour market policies in Belgium. Even if this were the case, the findings imply that extending expenditures on temporary work experience programmes should be avoided.
} 
structural skill mismatch. In 1995 only $11 \%$ of public outlays to active labour market policies were spent on training for unemployed workers and for workers risking loosing their jobs. Another $14 \%$ are spent on the training of youth and to workers in employment. The remainder $75 \%$ is mainly spent on temporary recruitment subsidies or direct job creation in the public or non-profit sector (OECD 1997, p. 99).

There are, however, competing explanations compatible with the high degree of heterogeneity in the exit rates out of unemployment. If either too high labour costs or co-ordination failures induced by wage rigidities can explain unemployment persistence, job competition can cause heterogeneity in the exit rates. The idea is that in periods of high unemployment, high skilled workers fill vacancies intended for lower skilled workers and/or employers raise the required skill level of vacancies even if the job requirements are unchanged (van Ours and Ridder 1995). If this were the diagnosis of persistent unemployment economic growth rich in employment, be it by an across the board reduction of labour costs (Daveri and Tabelini 1997) or by a "two-handed growth strategy using both demand- and supply-side policy instruments" (Shadman-Mehta and Sneessens 1998), is sufficient to cope with unemployment persistence and to simultaneously improve the relative position of the less skilled workers in the labour market. There is no need for targeting the job creation. Furthermore, training policies targeted on particular groups would be inefficient, as they would only lead to a redistribution of unemployment between different categories of workers.

Unfortunately, it is difficult to disentangle whether it is skill mismatch or job competition that is the principal cause of the heterogeneity in the exit rates out of unemployment. Dejemeppe and Cockx (1998c), for example, show that both models can reproduce the observed exit rates out of unemployment. Identification requires either to constrain the empirical model by imposing further theoretical restrictions or to add information on the skills requirements of the vacancies filled by unemployed workers. Further research is required on this issue.

We conclude that the design of active labour market policies depend on the diagnosis of the causes of the high persistent unemployment in Europe. This diagnosis may vary between countries in the EU. One should therefore avoid imposing uniform guidelines on the design of active labour market policies in the member states of the EU.

\section{Incentives: Do they matter?}

\subsection{Incentives for Unemployed Workers}

Economic analysis has paid much attention to the question of adequate incentives for unemployed workers. In essence the objective of this line of research searches for a design of benefit schemes that tries to hold unemployed workers responsible for the cost that their unemployment imposes on society. Unemployed workers can only be held responsible for costs of which they have control. However, the diagnosis of unemployment persistence in countries such as France or Belgium suggests that the majority of the unemployed workers do not have any control of these costs. Be it as a consequence of structural skill mismatch or of job competition, there is insufficient demand for low-skilled workers in these countries. Inducing the low-skilled unemployed workers to search harder for jobs or mandating participation to work experience programmes is therefore not going to make much of a 
difference. Moreover, mandating participation to training programmes can be counterproductive. For, the mandatory nature of the programme will distort allocative efficiency and induce revolting behaviour. This does not mean that adequate incentives for unemployed workers do not matter at all. It is rather a question of priority. Incentives may matter once the low skilled worker regains control over his situation. But this is presently not at issue.

There is a second reason why unemployed workers may be out of control of the social costs that unemployment imposes on society. Programme administrators can inhibit workers to participate in labour market programmes, even if their participation is socially cost-effective. Alternatively, programme administrators can mandate participation of workers for whom participation imposes a cost on society. The reason is that program administrators may use a programme to serve their own objectives, rather than those of the programme. In such cases providing correct incentives to unemployed workers is again not a priority. One first needs to align the objectives of administrators to those of society.

\subsection{Incentives for Programme Administrators}

We start off with a case study that demonstrates how adverse incentives for programme administrators can indeed render a programme ineffective. Next, we show, on the basis of a second case study, that programme objectives can be attained, even if there is no explicit monetary incentive scheme that point administrators in the "right" direction. Finally, we investigate the implications of these findings for the design of performance standard systems in labour market programmes.

\section{a) Case-Study 1: A Work Experience Programme for Welfare Recipients in Belgium}

In this first case study we summarise the findings of Cockx and Ridder (1998). In this study we estimate, for the June 1987 - July 1990 period, the effect of a subsidised public sector work experience programme without training content, henceforth "Social Employment" (SE), on the transition rate out of welfare (public assistance) in Belgium. As discussed in Section 2, such programmes can cope with sources of unemployment persistence induced by a process of discouragement, of loss of work habits or of skill deterioration. We argued, however, that for Belgium this couldn't be the major source of unemployment persistence. On this basis, we cannot expect Social Employment to have much of an impact on the transition rate out of welfare.

The study finds that participation in SE increases welfare duration. The time spent on the programme is included in this duration ${ }^{4}$. For a programme with some training content, this finding would not be troublesome. For, in that case, participation in the programme is an investment in human capital, the returns of which are reaped in the long run. As already mentioned, SE is a programme without any training content. However, one could object and argue, even if there is no explicit training component, that the investment in human capital is implicit. The acquisition of good work habits for disadvantaged workers, who have been out of work for a long time, can produce similar effects as training, delaying entry on the labour market in the short-run, but paying-off in the long-run by increasing the accessibility to jobs of

\footnotetext{
${ }^{4}$ The data did not allow measuring the long-run impact of SE on the transition rate out of welfare.
} 
a higher quality. Research in the US has shown that work experience programmes may indeed, in the long run, lead to sizeable earnings increases and to significant reductions in the probability of being on welfare. The National Supported Work (NSW) Demonstration is the prototype programme of this kind (see Hollister, Kemper and Maynard 1984, Grossman, Maynard and Roberts 1985, Gueron and Pauly 1991, and Couch 1992). However, this programme is characterised by two essential features that aren't shared by SE. First, NSW is targeted on extremely disadvantaged welfare recipients ${ }^{5}$. Second, the work experience programmes offered by NSW were highly structured: a full-time work experience position for up to a year or 18 months under conditions of gradually increasing demands, close supervision and peer group support (Gueron and Pauly 1991, p. 101). We show below that SE lacks these features. This is important, since evidence of other US programmes shows that if participants are not assisted or if work experience is provided to job-ready workers no programme impacts are found (Gueron and Pauly 1991).

One could also argue that the finding that participation in SE lengthens the welfare spell merely reflects that participants are better off than non-participants are, since participants are paid the minimum wage, providing them with significantly higher earnings than the welfare allowance. This difference in compensation level induces reductions in search effort. Moreover, job search effort is directly affected in that one cannot search for a job during working time. Even if this is true, this means that the programme is not well designed. For, this implies that the job experience programme induces dependency, the phenomenon it precisely ought to tackle.

The programme thus provides incorrect incentives to participants. However, this malfunctioning is reinforced by adverse incentives facing programme administrators. These can save significantly on outlays by hiring programme participants as cheap labour. To explain this point, we describe the main institutional features of the programme.

In Belgium the welfare system is a safety net for those who are not covered by social insurance. These persons are generally not covered as a consequence of insufficient work experience, of delay in administrative procedures, or because they have been punished by the social insurance administration. If they pass a means test, individuals can claim a supplement to their income up to the legally determined Minimum Income Guarantee (MIG)I at the welfare agency (WA) of their municipality. . During the 1987-90 period on average 52,659 adults and 31,672 children received the MIG at each instant of time (Cockx 1992, p.36). This is roughly $0.8 \%$ of the Belgian population. To compare, in January 1989389,672 individuals received allocations of the Unemployment Insurance programme (Cockx 1992, p.39). The relatively low proportion of welfare recipients results from the institutional setting in which workers remain entitled to unemployment insurance benefits for an indefinite duration ${ }^{6}$. In addition, after a waiting period of six months, school-leavers are entitled to unemployment insurance benefits.

Legislation stipulates that WA's may employ welfare recipients in order to entitle them to social insurance benefits. In particular, if this employment lasts sufficiently long ${ }^{7}$ it entitles the

\footnotetext{
5 NSW was provided to women entitled to Aid to Families with Dependent Children (AFDC) and to disadvantaged youth. Evaluation studies do not find any positive effects for the latter group, however.

${ }^{6}$ There is one exception to this rule. Cohabitants who are not the head of a family can lose entitlement to unemployment benefits on grounds of "excessive" duration.

${ }^{7}$ Unemployment benefits are only paid to workers who, within a specified period prior to their claim, have been employed for at least 75 days if younger than 18, and up to 600 days if older than 50 (Van Langendonck 1991, p. 450).
} 
employee to unemployment benefits. This is what is referred to as Social Employment (SE). During the 1987-90 period on average 1282 individuals received SE at each instant of time. This is $2,4 \%$ of the adult recipient population.

The possibility to employ welfare recipients for this purpose brought legislation into agreement with the principle that social assistance offers relief only if the main social insurance system fails to do so. The national and regional ${ }^{8}$ authorities have gradually widened the scope of SE to a means of enhancing the "social-professional" integration of the poor. This was reflected in increasing levels of financial support to WA's offering SE. The regional authorities subsidise SE in Flanders since 1983 and in the Walloon provinces since 1989. The central authorities finance $50 \%$ of the MIG paid by the local WA. Since 1985, the WA remains entitled to this subsidy even if a welfare recipient participates in SE. Since January 1993, the latter subsidy increased up to $100 \%$ of the MIG. It is important to realise that the WA's receive this financial support and not the employed welfare recipients

Van de Velde (1990) demonstrates that SE is concentrated in the community services that the WA offers to the general public. These community services consist of domestic services to households, such as care, meal provision, cleaning, and to institutions, i.e. nurseries, hospitals, elderly homes, etc. These jobs require few qualifications. Women are typically (95\%) employed in the domestic services provided by the WA. This work involves cleaning, cooking, washing and ironing. Men are required to do all kinds of odd jobs (37\%), to maintain roads or to plant vegetation (13\%), to help in the kitchen (10\%), to do administrative work (10\%) (see Van de Velde 1990, p.55).

WA's can save on outlays by employing welfare recipients. An example clarifies this point 9 . Consider a welfare recipient living alone somewhere in Flanders in January 1989. The net monthly cost of SE for this individual is the cost of the minimum wage for the employer $(=49,354$ Belgian Francs) minus the central authorities' subsidy amounting to $50 \%$ of the MIG $(=8,152 \mathrm{BEF})$ and the regional authorities' subsidy (=30,500 BEF): 10,702 BEF. Moreover, during the initial period of SE, during which the participant would otherwise depend on welfare, the WA no longer needs to pay welfare benefits and therefore saves additionally at least $^{10} 50 \%$ of the MIG $(=8,152 \mathrm{BEF})$ minus the regional subsidy for welfare $(=1,141 \mathrm{BEF})$, that is 7,011 BEF. This implies that employing in SE a worker, who initially produces goods and services with a value of more than 3,691 BEF per month and later on of more than 10,702 BEF per month, is financially attractive to the WA. The WA need not worry about costs after SE, because after SE welfare recipients are entitled to social insurance benefits, and hence will not depend financially on the WA. We conclude that SE can result in savings for WA's. These savings are larger if the WA "cream skims" the most productive recipients for participation in the programme.

This observation is not only valid for the specific example. However, the magnitude of the savings differs with the level of the $\mathrm{MIG}^{11}$, the time period and the region. For instance,

\footnotetext{
${ }^{8}$ Readers who are familiar with the Belgian institutional setting will notice that we use "regional" in a loose sense. As such, we can divide Belgium into 4 "regions": "Flanders", referring to the Flemish (Dutch) speaking community in the North; "the Walloon provinces", referring to the French speaking community in the South; "Brussels", referring to the region of the bilingual community of the capital city; "the German speaking community" in the East. Given the marginal importance of the latter region, we ignore it in the sequel.

${ }^{9}$ The figures in the example are taken from an internal document of a WA to which we had access.

${ }^{10}$ WA's can offer a supplement to the MIG financed out of their own means.

${ }^{11}$ The level of the MIG is different according to household type. Legislation distinguishes between singles living alone, singles living with dependent children, cohabiting individuals and cohabiting married couples.
} 
Brussels does not provide a specific subsidy for SE and due to the growing popularity of the programme in Flanders the level of the subsidy per participant declined over time. In the case of a lower subsidy the WA can maintain savings by being more selective in the choice of participants. The specific subsidy rules provide no incentive to the WA to use SE as a means to integrate welfare recipients in the labour market. Any effort to this effect will only increase its expenditures. Consequently, the findings of Van de Velde (1990, p. iv), that SE was hardly accompanied by training and assistance and that the WA's encouraged only $6 \%$ of the participants to apply for another job, are not surprising.

On the basis of these observations, we conclude that one can hardly expect SE to enhance integration and to reduce welfare dependency. The new programmes introduced in January 1989 , in which SE is supplemented by intensive assistance and training may have different effects. However, since participation by WA's in these programmes is voluntary, they are unlikely to be implemented by a majority of the WA's as long as subsidy rules allow WA's to save on outlays by hampering the professional integration.

In order to investigate these claims, we need an estimator of the effect of SE that is free of selection bias. This study proposes an instrumental variable (IV) estimator, called the Efficient Wald Estimator (Wald 1940, Angrist 1991), for this purpose. This IV estimator exploits that the participation rates in SE vary exogenously over the regions. This is because the subsidies of the regional authorities are exogenously determined, i.e. that they are determined without taking the exit rate from welfare into account. The regional variation in the subsidy rates is thus a "natural experiment" inducing exogenous variation in the participation rates in SE, required for identification of the treatment effect. The interested reader is referred to Cockx and Ridder (1998) for further details.

The estimation results can be summarised as follows. If we correct for selection on observable variables only participation in SE reduces the median welfare spell from 13.1 to 11.6 months ${ }^{12}$. The corresponding coefficient is significantly different from 0 . If we also correct for selection on unobservable variables, we find evidence for substantial cream skimming in the selection process. Participation in SE is now found to reduce the exit rate from welfare, be it that the effect is not significantly different from 0 . The median duration of a welfare spell is 12.5 months for non-participants and 14.8 months for participants in SE. This effect is shown to be stable a sensitivity analysis in a number of alternative directions. Moreover, we argue that it is not affected by Heckman's (1997) recent critique on IV estimators ${ }^{13}$.

These results are in line with the expectations. On the one hand, if skill-mismatch is the cause of unemployment persistence, rather than the process of discouragement, of the loss of work habits and of skill deterioration induced by unemployment and/or welfare dependency, work experience programmes are unlikely to have much of an impact on exit rates. On the other hand, as argued above, WA's face adverse incentives. Since the welfare recipient who is in SE will eventually become entitled to unemployment benefits, and will therefore no longer depend on the WA, the WA has no incentive to enhance the professional integration of the participants in SE. Moreover, since the SE is heavily subsidised, the WA has an incentive to enrol welfare recipients into the programme and to keep them employed in order to do jobs requiring few qualifications at a very low cost. The more the WA selects the most productive welfare recipients, the more it can profit from this programme. With the current incentives to the WA's it is very unlikely that the welfare recipient gain from participation in SE.

\footnotetext{
${ }^{12}$ The median duration refers to a welfare recipient in Flanders, who is selected into SE after 6 months.

13 We will return to this critique in more detail below, where we present our second case study.
} 
It is important to realise that the adverse incentives, described for this programme, are not singular to the programme studied here. In Europe, many direct job creation programmes in the public or the non-profit sector, but also systems of recruitment subsidies to the private sector, share common features. For instance, in Germany the dramatic rise of unemployment since the early nineties has substantially increased the number of welfare recipients. In order reduce budget deficits induced by the increasing caseloads, several municipalities, like Leipzig, Frankfurt or Lübeck, have started to offer temporary employment to welfare recipients in municipal job-creation companies, the so-called "Beschäftigungsgesellschaften". Feist and Schöb 1999 argue that municipalities can gain from such a reform and this for reasons that resemble very closely the Belgian situation. First, the job-creation companies provide local public goods. Second, after being employed for a year these wokers are entitled to unemployment insurance benefits of the "Bundesanstalt für Arbeit", a federal authority ${ }^{14}$. Consequently, the German municipalities have similar adverse incentives as WA's have in Belgium and German programme participants are unlikely to benefit very much of it ${ }^{15}$.

The British Youth Training Scheme (YTS) of the second half of the eighties provides an example in which private employers face adverse incentives. Participants in the YTS are placed in a job where they can acquire work experience. Trainees were paid an allowance (set slightly above the unemployment benefit level) and firms could employ trainees without incurring any further wage costs. As the WA's in Belgium, firms could therefore gain from cheap labour. Moreover, firms did not have explicit incentives to increase the employability of trainees. The work experience was supplemented by periods of classroom training, but one can have serious doubts on the quality of this training component, as this was a constant theme in discussions of reform. Dolton et al. (1994) find that ex-trainees obtain jobs at a slower rate than non-trainees even when the time spend on YTS is excluded ${ }^{16}$.

Work-experience programmes with little training content have been found ineffective in other European studies ${ }^{17}$. These studies do not mention the disincentive effects of programme administrators. However, to the extent that participants are employed in unqualified jobs, not requiring the employer to invest in (costly) firm specific skills, the employers have incentives to hire overqualified workers and discourage job search in order to benefit as much as possible from the cheap labour. When the subsidy comes to an end the employer who did not invest in the skills of the worker has no incentives to keep the worker. At the same time, an unskilled participant may have virtually no opportunity to be employed in a unsubsidised job and prefers the job to unemployment because of the higher earnings.

Compatible with this hypothesis, Edin and Holmlund (1990) report that participation in temporary jobs in the public sector in Sweden decreases the re-employment rate of young and

\footnotetext{
${ }^{14}$ The authors also mention a third reason why municipalities gain from this reform. Welfare recipients who refuse a job are considered unwilling to work and loose the entitlement to benefits. Moreover, the threat of mandatory participation intensifies job search of welfare recipients. If so, these gains should be traded-off against the welfare costs of mandatory participation. In Belgium, even if participation is also mandatory, this threat effect is negligible, because only a very small fraction of welfare recipients is proposed participation in SE.

${ }^{15} \mathrm{We}$ are not aware of any study evaluating this program. Eichler and Lechner (1998) find that public employment programs reduce the unemployment risk for participants in the East German State of SachsenAnhalt. However, this study could not distinguish employment in the municipal Beschäfti-gungsgesellschaften from other public employment programs.

${ }^{16}$ Female ex-trainees obtain 'good' jobs at a faster rate than non-trainees when time spent on YTS is_excluded. YTS confers no such advantage on men.

${ }^{17}$ Ridder (1986) finds positive employment effects of recruitment effects in the Netherlands. However, he does not correct for selection on unobservables which may bias his estimator.
} 
displaced workers ${ }^{18}$. Bonnal et al. (1997) find that in France unskilled young workers without any degree participating in public employment programmes do not increase the subsequent (after programme participation) transition rate from unemployment to employment. Moreover, participation decreases this transition rate for workers with a professional or technical diploma. The authors claim that the latter finding suggests that participation in such programmes signals low job performance.

\section{b) Case Study 2: Vocational Training for Unemployed Workers in Wallonia (Belgium)}

Cockx and Bardoulat (1999) estimate, for the 1989-1993 period in Wallonia ${ }^{19}$, the effect of vocational training for unemployed workers on unemployment duration. As in the previous study, the time spent on the programme is included in this duration. Again the study considers only the short run impact of training on the transition rate out of unemployment. This is justified in that the literature (see Heckman, Lalonde and Smith 1999 for a survey) generally reports that classroom training increases the employment probability and not so much the earnings or the length of employment spells.

In Wallonia the regional public employment agency, FOREM, is the main operator of vocational classroom training for adult unemployed workers ${ }^{20}$. For this purpose, it has a chain of training centres at its disposal widely dispersed over the territory of the Walloon region. FOREM provides vocational training for a wide range of professions of the secondary (FP II) and tertiary sector (FP III). Apart from vocational training, it also offers services information, vocational guidance and work experience to a more disadvantaged population of unemployed workers in its Centres of Reception, and of Guidance and Socio-Professional Initiation (C.A./C.O.I.S.P). During the 1989-93 period, about two thirds of the available training slots are of the vocational type, each sector being equally important. In terms of hours of training, the share of vocational training increases to $85 \%^{21}$. The level at which vocational training is offered varies, but the majority of the programmes consists in the development of basic skills required in particular vocations. The data that were used for the evaluation study did not allow distinguishing between the different programme types. The estimated effect of participation to training is therefore necessarily an average effect over the wide variety of programmes offered.

What determines participation into these training programmes? In principle no restrictions are imposed. Participation is voluntary and any unemployed worker can apply. However, eligibility requires candidates to pass tests on basic reading and writing when applying for a training programme in the tertiary sector and on calculation in the secondary sector. In addition, they need to pass medical and psycho-technical tests. These tests are uniform over training centres and types. Subsequently, programme administrators select candidates on the basis of some vague criteria as "motivation". Finally, because there is an excess demand for

\footnotetext{
18 The authors also find that program participation reduces the length of subsequent unemployment spells. However, the study imposes strong parametric (Weibull) restrictions on the baseline hazard and does not explicitly account for selection on unobservables, which may bias the results.

${ }^{19}$ The French speaking region in the south of Belgium.

${ }^{20}$ More details of the institutional framework can be found in OCDE (1997).

${ }^{21}$ In the sequel figures for which no source are mentioned are taken from FOREM (1989-94) or from unpublished document of the employment agency.
} 
training, candidates are registered on a waiting list ${ }^{22}$ until a new training session of their choice starts off.

Training centres, nor administrators or instructors are in any way rewarded on the basis of placement ratios or to other labour market outcomes. Consequently, direct incentives to cream-skim candidates, likely to find jobs even without participation in the programme, are absent. Even if we cannot evaluate for certain the implicit selection criteria of the programme administrators, selection seems therefore rather to be based on criteria that affect the returns to training than on the absolute employability of the worker.

Workers are not only selected into the programme, however. The costs imposed on the participation in a training programme induce a process of self-selection. Only workers with high returns to training can compensate for these costs and participate. Participation costs are partially reimbursed to the participant. First, a trainee remains entitled to unemployment benefits. Moreover, he/she is paid $40 \mathrm{BEF}$ (=1 EURO) for each effective training hour and is reimbursed transportation costs. The candidate trainee must, however, bear two main costs: the application costs and the earnings forgone during the period in which the candidate trainee is waiting to enter training. The application costs are the cost of gathering information on the programme, as well as the time, effort and transportation costs of the higher mentioned test and interview. Second, as a consequence of the limited training capacity, the candidate must be ready to wait before he or she can participate in training. This means that participation in training requires the worker to reject job offers during this waiting period.

Trainees are therefore a selected and not a random sample of the population of unemployed workers. If one wants to estimate the effect of participation in training on the probability to leave unemployment, one therefore inevitably face the problem of potential selection bias. In order to find an estimator that is free of selection bias, the authors also exploit a natural experiment, inducing sub-regional variation in the participation rates that is not, directly or indirectly, caused by the sub-regional variation in the exit rates. Since the demand for training always exceeds the supply, the variation in the number of trainees across sub-regions is completely determined by the training capacity of the training centres. This training capacity is in turn determined by the budget of the local training centres. We mentioned higher that this budget is in no way related to placement ratios and other labour market outcomes. Interviews of employees of the employment agency, FOREM, revealed that the sub-regional variation in training budgets does not depend on any objective criteria, but merely reflects the history of political power of the respective sub-regions. Even if there is no direct effect, the sub-regional level of the transition rate out of unemployment could have indirectly influenced the number of available training slots. In order to preclude this possibility, the authors examined whether variations in training capacities over time were in any way systematically related to the subregional state of the labour market, both during and prior to the observation period. The findings reveal no such systematic relationship (see Cockx and Bardoulat 1999 for further details). This indicates that the sub-regional variation in the number of trainees is exogenous to the variation in the exit rates.

In contrast with case study 1 , an IV estimator that exploits the exogenous sub-regional variation in the participation rates will nevertheless not yield a consistent estimator of the impact of vocational training on the transition rates out of unemployment. This is because consistency of the IV estimator requires that the returns to treatment are homogeneous or that

\footnotetext{
${ }^{22}$ We do not have any information on the length of this waiting period.
} 
personal specific responses to treatment do not influence decisions to participate in the programme (Heckman 1997). We argued above that returns to training vary between participants and that workers with higher returns to training are more likely to participate. Consequently, to the extent that these returns are positively correlated with the impact on the transition rate out of unemployment, an estimator that ignores this issue will over-estimate the impact of vocational training on an average unemployed worker. Moreover, even if one is only interested in the average impact of those who did participate in training, the IV estimator, based on the exogenous variation of programme participation rates between sub-regions, will be inconsistent. For, in sub-regions with a relatively high training capacity and therefore with a relatively high number of trainees, the costs to programme participation will be lower than in regions with relatively low participation rates. If the cost of programme participation is lower in the former sub-regions, these sub-regions will also have more trainees with relatively low returns. Consequently, sub-regions with a high training capacity will exhibit lower returns, on average, than sub-regions with a low capacity. This overturns the exogeneity assumption of the sub-regional variation in the number of trainees.

Cockx and Bardoulat (1999) therefore developed a "control function estimator" exploiting the higher mentioned natural experiment to identify the impact of training, but also explicitly accounting for the variation in the personal specific responses to treatment. In the paper a parametric specification of the distribution of these personal specific responses was imposed. The best fit was obtained by specifying an exponential distribution ${ }^{23}$. Further details can be found in Cockx and Bardoulat (1999).

The authors estimate the short run impact of training on the transition rate out of unemployment. They distinguish between the impact of training during participation on the programme $^{24}$ and the impact after participation for those trainees who returned to unemployment afterwards. If training were to be provided to all unemployed workers, they find that during participation the transition rate out of unemployment would decrease by $5 \%$ on average. However, this impact is not significantly different from zero. For those who would return to unemployment afterwards, the transition rate out of unemployment is on average $13 \%$ higher.

The reported impacts are, however, average effects of training if all unemployed workers would participate to training. In reality, only about $3.5 \%$ of the unemployed workers participate or have participated in training at any instant of time. Since participants have higher returns to training than non-participants do, we expect the impact of training for the effective participants to be much higher than those reported above. Moreover, the higher mentioned estimated impacts are extrapolations that crucially depend on the parametric specification of the distribution of the personal specific responses to training.

The paper therefore also reports the average effect of training on those who were effectively treated. Participation decreases the rate at which unemployment is left by $27 \%$. After participation, the transition intensities increase by a factor 1.62. This demonstrates that the described training programme significantly decreased unemployment duration of participants. Finally, note that the study does not find any evidence of trainees being selected on the basis of unobservable characteristics.

\footnotetext{
${ }^{23}$ Other distributions, such as the normal, the uniform and a piecewise-constant exponential distribution were also tried out, but these specification could be rejected against the exponential specification.

${ }^{24} \mathrm{We}$ could not distinguish between trainees leaving the training programme before it ends and those who complete the programme.
} 
What can we conclude from the positive findings of this case study? The findings suggest that it is more important to avoid that programme administrators are affected by adverse incentives, than to introduce an explicit performance standard system to induce programme administrators to behave in line with the programme's objectives. The first natural question to ask is then: Why is this so? The second question is can an explicit performance standard system improve upon these results, and if so, how should this system be designed? Although we cannot provide definite answers to these questions, we will provide some suggestive answers that, to our opinion, merit further research.

First, we believe that part of the success of this Belgian training programme is due to the capacity constraints of the training centres rather than a consequence of well designed incentives to programme administrators. These capacity constraints have imposed significant costs on programme participation, because candidate trainees may have to wait quite a long time before they can effectively engage in training. This is costly, because they need to forgo the earnings of jobs offered during this waiting period (otherwise they forgo the benefits of participating in training). The high cost has the beneficial effect of inducing a self-selection process by which only workers with high returns to training participate. Of course, the advantages of this enhanced targeting need to be traded-off against the social cost of the increased unemployment duration implied by the waiting period. It would be interesting to investigate the conditions under which a deliberately chosen waiting period would lead to a social optimum. Note that the formal structure of this problem resembles very much that of models that justify the use of benefits in kind to increase the targeting efficiency. Indeed, as benefits in kind impose an "ordeal" by restricting the choices of beneficiaries, the waiting period imposes an "ordeal" on the candidate trainees (Nichols and Zeckhauser 1982 and Blackorby and Donaldson 1988).

Another way to explain the positive results in the absence of explicit monetary incentives is that there are implicit non-monetary incentives inducing programme administrators and instructors of the training programmes to behave in line with programme objectives. These non-monetary incentives can consist in the intrinsic motivation of programme administrators, but also in professional standards implicitly imposed by peer comparison or in social norms imposing workers to obey to instructions. These kinds of non-monetary incentives will not be effective for all types of workers. It can be argued that they will have more impact on workers who have chosen to work in relatively low paying jobs of organisations pursuing "social" objectives. These kinds of jobs are more likely to be found in the public sector and in the nonprofit sector, than in the private for profit sector. The higher mentioned indications of a social worker mentality among programme administrators, inducing them to help the most disadvantaged workers, provides a signal that the employees of the training centres of FOREM are indeed sensitive to these kinds of non-monetary incentives. Economists know little about the conditions under which such non-monetary incentives work and about whether and how they could be shaped to attain pre-specified objectives. In my opinion, this is a promising research area.

\section{c) The Design of Performance Standards Systems for Labour Market Programmes ${ }^{25}$}

The first case study has shown that adverse incentives for programme administrators may be particularly harmful for the good functioning of a programme. This suggests that the

\footnotetext{
${ }^{25}$ This section is to a large extent based on Heckman et al. (1997).
} 
introduction of performance standards that align objectives of administrators to those of the programme is crucial. This requires, however, that the goals be not only clearly defined, but that they can be measured. Since programme objectives are often the outcome of a political process involving compromise among competing fractions with different objectives, the objectives are often not clearly defined. Moreover, even if goals are clearly defined, these are often stated in terms of unobserved net social benefits. Performance-standards targets need, in contrast, to be written in terms of measured levels. These measured levels can differ significantly from the unobserved programme objectives. This difference can be induced by the higher mentioned selection bias, causing observed differences in outcomes between programme participants and non-participants to diverge from the programme impact. Alternatively, it can be caused by the need to define a more operational measure that is not directly related to the unobserved programme goal. For instance, performance-standards systems typically use short-run rather than long-run measures in order to provide quick feedback to programme managers, even though long run measures more closely approximate the notion of social benefit (Heckman et al. 1997, p. 390). Finally, if programme objectives and performance measures diverge, programme administrators may "game" incentive schemes to maximise their personal rewards (Ibid. p.391).

Heckman et al. (1997) assess the performance of the performance standards systems of the Job Training Partnership Act (JTPA) in the US. The JTPA runs the federal government's most important job-training programme for the poor. This study demonstrates that it is difficult to design adequate performance standards systems for labour market programmes that point administrators in the "right" direction. The study shows, for instance, that many measures, used as standards for the JTPA incentive scheme, are actually negatively related to the programme's long-run impact on trainees. "The performance standards system motivates therefore administrators to pursue outcomes unrelated, or even negatively related, to a major programme goal" (Heckman et al. 1997, p.391). Moreover, Courty and Marschke (1997) provide ample evidence that programme administrators game the incentive schemes, leading to wasteful activity.

Designing adequate performance systems for labour market programmes is difficult. This difficulty underlines the importance of looking for alternative ways to align the behaviour of administrators to programme objectives. One way to go, is to search for easily measurable indicators that exhibit a strong correlation with programme objectives. Another way is to try to obtain a better understanding in how non-monetary incentives work. The second case study suggests that these non-monetary incentives might partly explain the success of the training scheme. Heckman et al. (1997, p.392) also stress that "the behaviour of employees of bureaucracies is influenced not only by incentives controlled by the agency, but also by their attitudes, ideology, and by the standards of external reference groups, such as the professional mores of social workers". Moreover, the authors argue that the JTPA objective to enrol the least advantaged into the programme is probably assured by the social worker mentality of most "street-level" bureaucrats, rather than by the incentive schemes.

\section{Conclusion}

In this paper we provided some guidelines for an efficient design of active labour market policies. First, we emphasised that the optimal design of these policies crucially depends on the main causes of unemployment persistence. Each diagnosis matches an alternative design. Second, we stressed the importance of providing adequate incentives for programme 
administrators of active labour market policies, and that this may well be more important than providing adequate incentives to the unemployed workers. To illustrate this point, we summarised two case studies evaluating active labour market policies in Belgium. The first one evaluated a work experience programme for welfare recipients. The second one analysed the short-term effect of vocational training programmes for unemployed workers on the probability of leaving unemployment. The first case study shows how inappropriate incentives to programme administrators may render a programme ineffective. In Europe, many direct job creation programmes in the public or the non-profit sector, but also systems of recruitment subsidies to the private sector, share common features of this adverse programme design. The second case study reveals how a programme without any explicit incentives can be effective. This finding was contrasted with the adverse effects found for U.S. training programmes, guided by an explicit system of performance standards. Both implicit non-monetary incentives and self-selection induced by a costly application process could explain the success of second case study. The challenge for economists is to obtain a deeper understanding of these factors of success.

\section{References}

Angrist, Joshua D. (1991), "Grouped-data estimation and testing simple labor-supply models", Journal of Econometrics, 47, 243-266.

Berman, Eli, Bound, John and Machin, Stephen (1998), "Implications of Skill-Biased Technological Change: International Evidence", Quarterly Journal of Economics, November.

Blackorby, C. and Donaldson, D. (1988), "Cash Versus Kind, Self-Selection, and Efficient Transfers “, The American Economic Review, Papers and Proceedings, 78(4), 691-700.

Blanchard, O.J. (1991), "Wage Bargaining and Unemployment Persistence”, Journal of Money, Credit, and Banking, 23, 277-292.

Blanchard, O.J. and Diamond, P.A. (1994), "Ranking, Unemployment Duration, and Wages ", Review of Economic Studies, 61, 417-434.

Blank, R.M. and Freeman, R.B. (1994), “Evaluating the Connection Between Social Protection and Economic Flexibility “, in Blank, R.M. (ed.), Social protection versus economic flexibility: Is there a trade-off?, University of Chicago Press, 21-41.

Bonnal, Liliane, Fougère, Denis and Sérandon, Anne (1997), "Evaluating the Impact of French Employment Policies on Individual Labour Market Histories", The Review of Economic Studies, 64, 683-713.

Booth, A.L. and Snower, D.J. (1996) (eds.), Acquiring skills. Market failures, their symptoms and policy responses, Cambridge University Press, Cambridge.

Calmfors, L. (1994), «Politiques actives du marché du travail et chômage - Cadre d'analyse des aspects cruciaux de la conception des mesures », Revue économique de l'OCDE, 22, 7-52. 
Cockx, Bart (1992), The Minimum Income Guarantee. Some Views from a Dynamic Perspective, Ph.D.-Thesis, Faculteit der Economische en Toegepaste Economische Wetenschappen, Katholieke Universiteit Leuven.

Cockx, Bart and Bardoulat, Isabelle (1999), “Vocational Training: Does it Speed up the Rate of Transition out of Unemployment",IRES and Department of Economics, Université catholique de Louvain, paper prepared for the ZEW Research Conference on "Econometric Evaluation of Active Labour Market Policies in Europe" June 24-25, Mannheim.

Cockx, Bart and Ridder, Geert (1998), "Social Employment of Welfare Recipients in Belgium: an Evaluation ", revision of Discussion Paper $n^{\circ}$ 9618, Institut de recherches économiques et sociales, Université Catholique de Louvain, Louvain-la-Neuve, presented at the Conference on Policies for Low-wage Employment and Social Exclusion in Europe, Groningen, 19-21 November 1998.

Couch, Kenneth A. (1992), "New Evidence on the Long-Term Effects of Employment Training Programs", Journal of Labor Economics, 10(4), 380-88.

Courty, P. and Marschke, G. (1997), "Measuring Government Performance: Lessons from a Federal Job-Training Program ", The American Economic Review, Papers and Proceedings, 87(2), 383-388.

Daveri, F. and Tabellini, G. (1997), “Unemployment, Growth and Taxation in Industrial Countries", mimeo, IGIER.

Dejemeppe, Muriel and Cockx, Bart (1998a), "La conception des politiques en faveur de l'emploi. L'importance d'un diagnostic des causes du chômage structurel ", Contribution au $13^{\text {ème }}$ Congrès des Economistes belges de Langue française, CIFoP, Charleroi, 26-27 November 1998.

Dejemeppe, Muriel and Cockx, Bart (1998b), "Duration dependence in the exit rate out of unemployment in Wallonia. Is it true or spurious?", paper presented at the 10th annual Conference of the European Association of Labour Economists, Blankenberge, 17-20 September 1998.

Dejemeppe, Muriel and Cockx, Bart (1998c), "Skill mismatch or crowding out in Belgium? ", paper presented at the Conference on Policies for Low-wage Employment and Social Exclusion in Europe, Groningen, 19-21 November 1998.

Dolton, Peter J., Makepeace, Gerald H., Treble, John G. (1994), "The Youth Training Scheme and the School-to-work Transition", Oxford Economic Papers, 46(4), 629-57.

Drèze, Jacques H. (1997), "Walras-Keynes Equilibria, Coordination and Macroeconomics", CORE Discussion Paper No. 9751.

Drèze, Jacques H., Malinvaud, E. et al. (1994), "Growth and Employment: The Scope for an European Initiative “, European Economy (Reports and Studies), 1, 75-106.

Drèze, Jacques H. and Sneessens, H. (1997), "Technological Development, competition from low-wage economies and low-skilled unemployment", in Snower, Dennis J. and de la 
Dehessa, Guillermo (eds.), Unemployment policy: government options for the labour market, Cambridge University Press, Cambridge, 250-81.

Edin, Pers-Anders and Holmlund, Bertil (1990), "Unemployment, Vacancies and Labour Market Programmes: Swedish Evidence", in Padoa Schioppa, Fiorella (ed.), Mismatch and Labour Mobility, Cambridge University Press, Cambridge.

Eichler, Martin and Michael Lechner (1998), "An Evaluation of Public Employment Programmes in the East German State of Sachsen-Anhalt", mimeo, Universität Mannheim/Universität St. Gallen.

Feist, Holger and Ronnie Schöb (1999), "Workfare in Germany and the Problem of Vertical Externalities", paper presented at the 11th EALE-conference, Regensburg, 23-26 September, CES, Ludwig-Maximilians-Universität München.

Gregg, P. and A. Manning (1996), "Labour market regulation and unemployment", in Snower, Dennis J. and de la Dehesa, Guillermo (eds.), Unemployment policy: government options for the labour market, Cambridge University Press, Cambridge, 395-424.

Grossman, Jean Baldwin, Maynard, Rebecca and Roberts, Judith (1985), Reanalysis of the Effects of Selected Employment and Training Programs for Welfare Recipients, Mathematica Policy Research, Inc., Princeton.

Gueron Judith M. and Edward Pauly (1991), From Welfare to Work, Russell Sage Foundation, New York.

Heckman, James J. (1997), "Instrumental Variables. A Study of Implicit Behavioral Assumptions Used in Making Program Evaluations", Journal of Human Resources, 32(3), 441-62.

Heckman, James J., Heinrich, Carolyn and Smith, Jeffrey (1997), "Assessing the Performance of Performance Standards in Public Bureacracies", The American Economic Review, Papers and Proceedings, 87(2), 389-95.

Heckman, James J., Robert J. Lalonde and Jeffrey A. Smith (1999), "The Economics and Econometrics of Active Labor Market Programs", in Ashenfelter, O. and D. Card (eds.), The Handbook of Labor Economics, North Holland, Amsterdam, 1865-2097.

Hollister, Robison G., Jr., Kemper, Peter, Maynard, Rebecca A. (eds.) (1984), The National Supported Work Demonstration, University of Wisconsin Press, Madison, Wis.

Layard, R., Nickell, S. and Jackman, R. (1991), Unemployment, Oxford University Press, Oxford.

Machin, Stephen and Alan Manning (1999), "The causes and consequences of longterm unemployment in Europe", in Ashenfelter, O. and D. Card (eds.), The Handbook of Labor Economics, Amsterdam: North-Holland, 3085-3139.

Nichols, A.L. and Zeckhauser, R.J. (1982), “ Targeting Transfers through Restrictions on Recipients “, The American Economic Review, Papers and Proceedings, 72(2), 372-377. 
OCDE (1997), Le Service public de l'Emploi. Belgique, OCDE, Paris.

OECD (1990), Labor market policies for the 1990's, Paris: OECD.

OECD (1994), The OECD Jobs Study: Facts, Analysis and Strategies, Paris: OECD.

Ridder, Geert (1986), "An Event History Approach to the Evaluation of Training, Recruitment and Employment Programmes", Journal of Applied Econometrics, 1(2), 109-126.

Shadman-Metha, F. and Sneessens, H.R. (1998), "Demand-Supply Interactions and Unemployment Dynamics: Can there be Path Dependency? The case of Belgium, 19551994", paper presented at the 10th annual Conference of the European Association of Labour Economists, Blankenberge, 17-20 September 1998.

Sneessens, H.R. (1994), "Courbe de Beveridge et demande de qualifications", Economie et Prévision, 113-14, 127-38.

van den Berg, Gerard J. and van Ours, Jan (1994), "Unemployment Dynamics and Duration Dependence in France, The Netherlands and the United Kingdom", The Economic Journal, 104, March, 432-43.

van den Berg, Gerard J. and van Ours, Jan (1996), "Unemployment Dynamics and Duration Dependence", Journal of LaborEconomics, 14(1), 100-25.

Van der Linden, Bruno and Eric Dor (1998), “ The effect of unemployment benefits, sanctions and training on unemployment outflows ", paper presented at the International Conference on Institutional and Financial Incentives for Social Insurance, PAI-UAP, Université catholique de Louvain, 11-12 December 1998.

Van de Velde, Veerle (1990), Wat na de sociale tewerkstelling? Evaluatie van de toepassing van art. 60 par.7 van de organieke wet op het OCMW, Hoger Instituut voor de Arbeid, Katolieke Universiteit Leuven, Leuven.

Van der Linden, Bruno (1997) (ed.), Chômage Réduire le fracture, De Boeck \& Larcier, Paris et Bruxelles.

Van Langendonck, J. (1991), Handboek Sociale Zekerheid, Acco, Leuven.

van Ours, Jan and Ridder, Geert (1995), "Job matching and job competition: are lower educated workers at the back of job queues?", European Economic Review, 39, 1717-1731.

Wald, Abraham (1940), "The fitting of straight lines if both variables are subject to error", Annals of Mathematical Statistics, 11, 284-300. 